\title{
Effect of a Corrective Exercise Program Based on Scapular Stability on Upper Cross Syndrome in Wheelchair Basketball Athletes
}

\section{ART ICLE INF O}

\section{Article Type}

Original Research

\section{Authors}

Maarouf A. ${ }^{* 1} P h D$

Norasteh A.A. ${ }^{1} P h D$,

Daneshmandi H. ${ }^{1} P h D$

Ebrahimi-Atri $\mathrm{A}^{2} \mathrm{PhD}$

How to cite this article
Maarouf A, Norasteh A.A, Danesh-
mandi H, Ebrahimi-Atri A. Effect
of a Corrective Exercise Program
Based on Scapular Stability on
Upper Cross Syndrome in Wh-
eelchair Basketball Athletes. Irani-
an Journal of War \& Public Health.
2020;12(1):19-27.

${ }^{1}$ Sports Injuries \& Corrective Exercise Department, School of Physical Education \& Sport Sciences, University of Guilan, Rasht, Iran

${ }^{2}$ Sports Injuries \& Corrective Exercise Department, School of Physical Education \& Sport Sciences, Ferdowsi University of Mashhad, Mashhad, Iran

\section{*Correspondence}

Address: Sports Injuries \& Corrective Exercise Department, School of Physical Education \& Sport Sciences, University of Guilan, Rasht, Iran. Phone: +98 (56) 32663870

Fax: +98 (56) 32663858 abed.maaroof93@Gmail.com

\section{Article History}

Received: August 10, 2019

Accepted: January 20, 2020

ePublished: March 17, 2020

\section{A B S T R A C T}

Aims Wheelchair basketball athletes, as a group of people with spinal cord injury, are at risk for upper cross syndrome. The purpose of the present study was to investigate the effect of a corrective exercise program based on scapular stability on upper cross syndrome in wheelchair basketball athletes.

Materials \& Methods In this semi-experimental study that was conducted in 2017-2018, 24 veteran and handicapped wheelchair basketball athletes who had spinal cord injury with upper cross syndrome in Mashhad were selected by purposive sampling method and divided into control $(n=12)$ and case $(n=12)$ groups. A corrective exercise program based on scapular stability were administered to the case group for 8 weeks. Camera and flexible ruler tools were used to measure forward head, rounded shoulder and kyphosis, respectively. Data analysis was performed by SPSS 23 software using independent t-test, paired t-test, one-way analysis of variance, and Tukey's post hoc test.

Findings The severity of forward head, rounded shoulder and kyphosis abnormalities was less in class 3 than in class 1 and 2. There was a significant difference between the case and control groups after training in all three forward head, rounded shoulder, and kyphosis abnormalities $(\mathrm{p}<0.05)$.

Conclusion The corrective exercises based on scapula stability are one of the most useful training methods for restoring muscle balance and preventing and correcting abnormalities in wheelchair basketball athletes.

Keywords Basketball; Wheelchair; Upper Limb Deformities; Head; Kyphosis; Exercise

\section{I T A T I O N L I N K S}

[1] Practical management: common medical problems ... [2] Practical management: common medical problems ... [3] Towards evidence-based classification in ... [4] The physically-challenged athlete: medical ... [5] The relationship of strength and muscle ... [6] Comparison of line of the spine veterans spinal ... [7] The survey of spinal alignment and physical fitness ... [8] The effect of childhood spinal cord injury ... [9] Seating and mobility considerations for people with ... [10] Wheelchair configuration and postural alignment ... [11] Muscles and cervical pain syndromes ... [12] NASM essentials of corrective exercise ... [13] Reliability and validity of thoracic kyphosis measurements ... [14] The effect of 6-week exercise therapy protocol ... [15] Comparison of the effects of three corrective exercise methods ... [16] The effect of six weeks corrective exercise on upper ... [17] The effect of eight weeks comprehensive ... [18] The comparison of effect of three programs ... [19] The effect of a NASM-based training protocol ... [20] Head and shoulder posture affect scapular mechanics ... [21] Cervical curve restoration and forward head ... [22] ACSM's guidelines for exercise testing ... [23] The effect of a 10-week selected corrective ... [24] Intrarater and interrater reliability of photographic ... [25] Gym based exercises for ... [26] Assessment and treatment of muscle ... [27] Thoracic position effect on shoulder range ... [28] The impact of kyphosis on daily ... [29] Spinal cord medicine, principles ... [30] The efficacy of forward head correction on nerve ... [31] Upper crossed syndrome and its relationship ... [32] Management of common musculoskeletal ... [33] The effects of a selective corrective program ... [34] Effect of stretching and strengthening shoulder ... [35] Surface electromyographic analysis of exercises ... [36] Effect of neck exercise on sitting posture ... [37] Recruitment of the deep cervical flexor muscles ... [38] Shoulder Function and 3Dimensional Kinematics ... [39] Muscle specificity in tests of cervical flexor muscle ... 
اندام فوقانى و گسترش ميكروتروما و آسيب مزمن در مج دست،

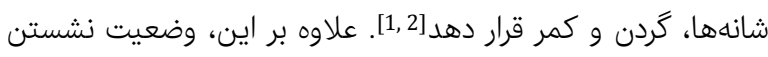
اين ورزشكاران، مخصوصاً افراد داراى ضايعه نخاعى، سبب تئ تيلت

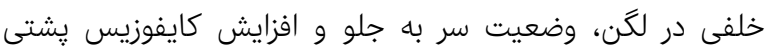

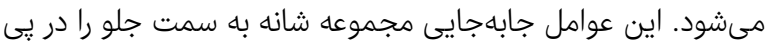

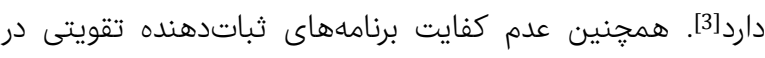

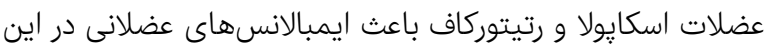

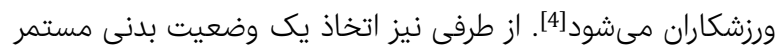

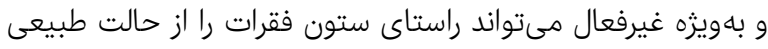

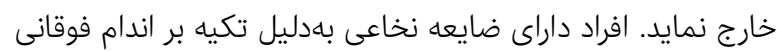

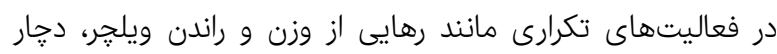
خستخى عضلانى و نهايتاً درد مى ماندوند ر5ائ.

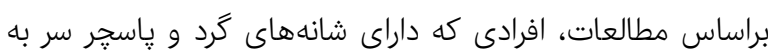

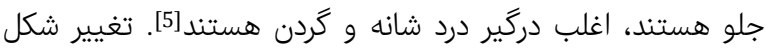

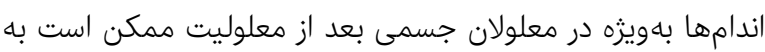
وجود آيد كه تغيير شكلهاى ستون فقرات درات نظير اسكوليوزيس،

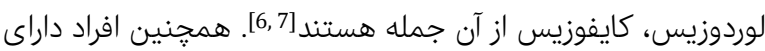

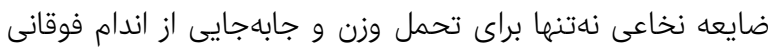

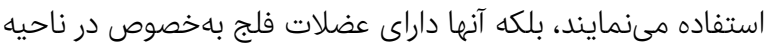

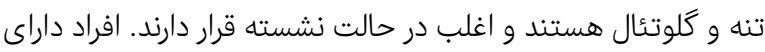

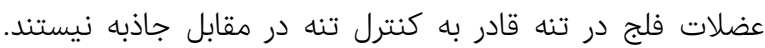

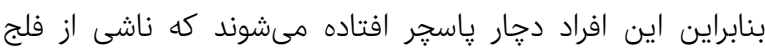

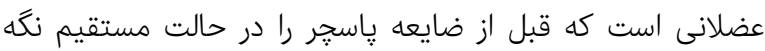

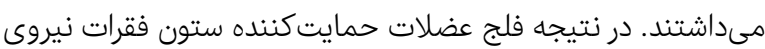

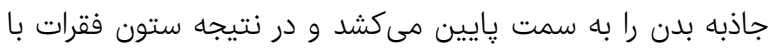

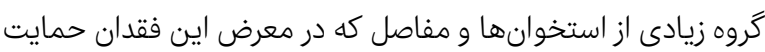

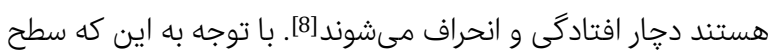
ضايعه بالاتر كروههاى عضلانى بيشترى را دركير مىنمايد، حمايت إنايت

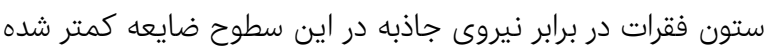
و بنابراين ميزان ناهنجارى در سطوح بالاتر داراى ضايعه بير بيشتر

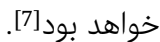

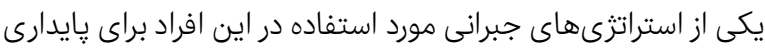

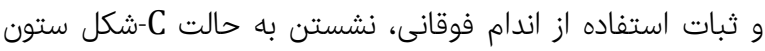

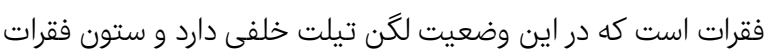

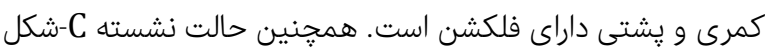

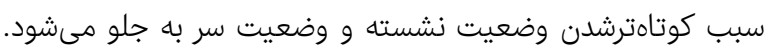
ناهنجارىهاى ناشى از اين نوع نشستن تقريباً شبيه افراد داراى

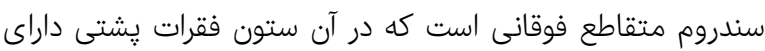

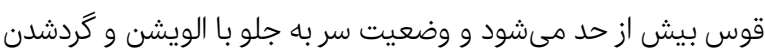

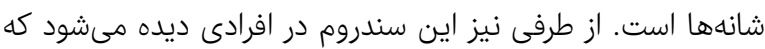

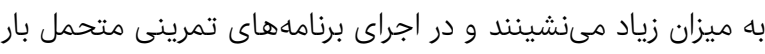

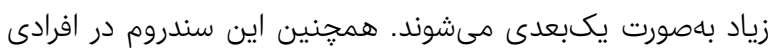

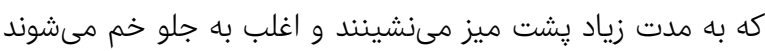
ديده مىشود[10,19]. اين سندروم يكى از الخَوهاى عدم تعادل
تاثير يك برنامه تمرينى اصلاحى مبتنى بر ثبات اسكايولا بر سندروم متقاطع فوقانى در ورزشكاران

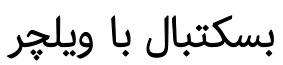

PhD عبدالله معروف

كروه آسيب شناسى ورزشى و حركات اصلاحى، دانشكده تربيت بدنى و و علوم

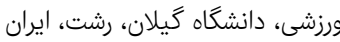

Pلى اصغر نورسته PhD

كروه آسيب شناسى ورزشى و ورسته حركات اصلاحى، دانشكده تربيت بدنى و علوم

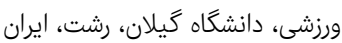

حسن دانشمندى PhD

كروه آسيب شناسى ورزشى و حرى حرات اصلاحى، دانشكده تربيت بدنى و علوم

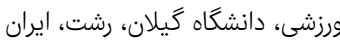

PhD احمد ابراهيمى دانشعرى

كروه آسيب شناسى ورزشى و وريمي حركات اصلاحى، دانشكده تربيت بدنى و علوم ورزشى، دانشگاه فردوسى مشهي، مشهيد، ايران حركات اصلاحي،

جكيده

اهداف: ورزشكاران بسكتبال با ويلجر بهاعنوان گَروهى از افراد داراى ضايعه نخاعى

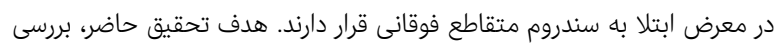

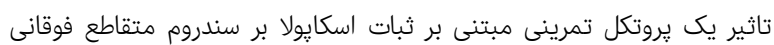

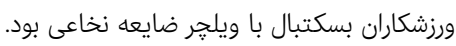

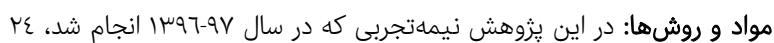

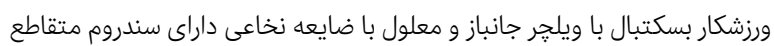

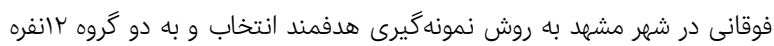

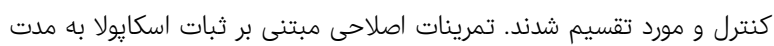

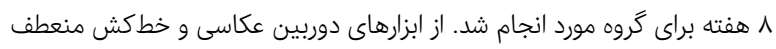

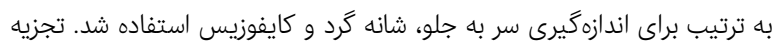

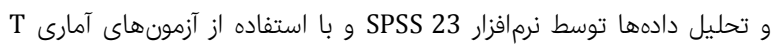

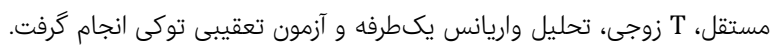

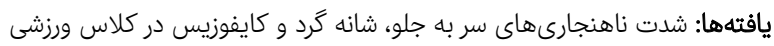

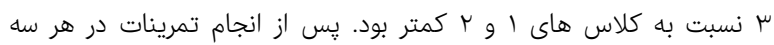

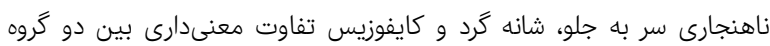

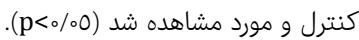

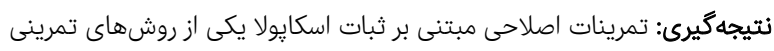

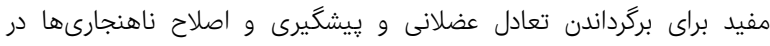

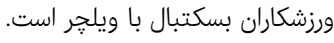
كليدواثمها: بسكتبال، ويلجر، ناهنجارىهاى بان اندام فوقانى، سر، كايفوزيس، تمرين

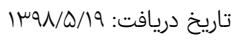

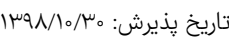

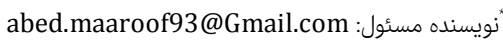

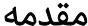

ورزشهاى ويلجرى مانند بسكتبال با ويلجر كه در يك زمين اجرا

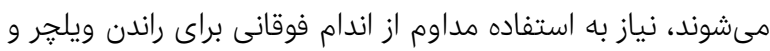

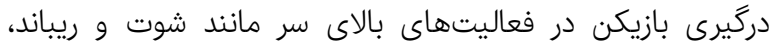
دسترسى به توب، مانور ويلجر و تعقيب بازيكن دريكن دارئ دارند كه ممكن است اين ورزشكاران را بهطور عمده در معرض آسيبهاى يركارى داري 


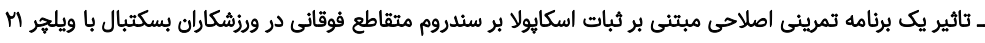

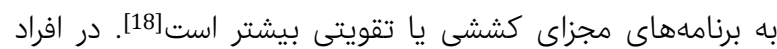

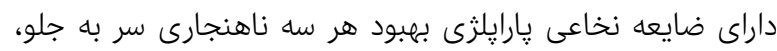

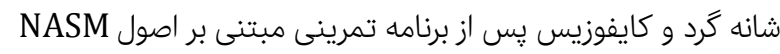

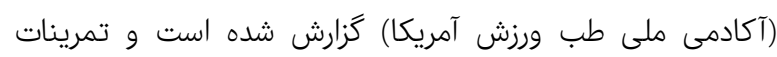

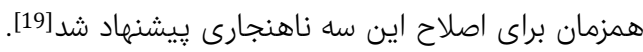

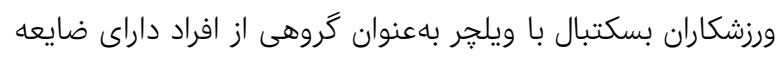

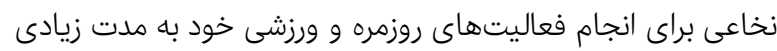

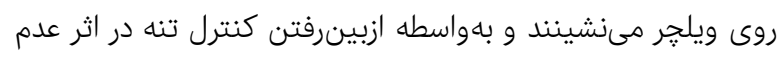

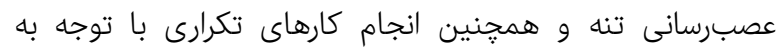
ماهيت رشته ورزشى در معرض ابتلا به سندروم متقاطع فوقانى قرار

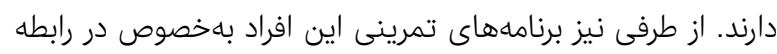

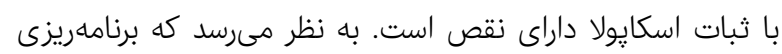

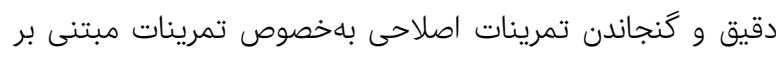

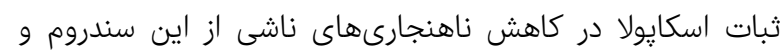

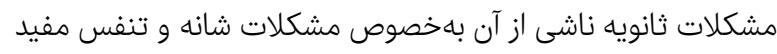

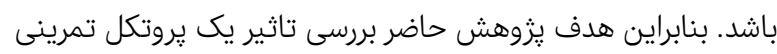

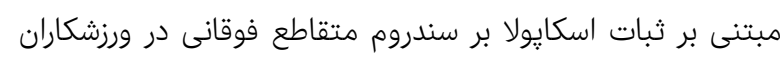
بسكتبال با ويلجر ضايعه نخاعى بود.

\section{مواد و روشها}

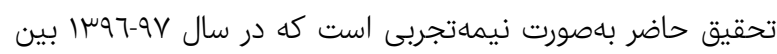
جانبازان و معلولان داراى ضايعه نخاعى ورزشكار در رشته بسكتبال

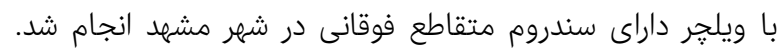

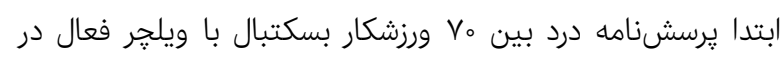

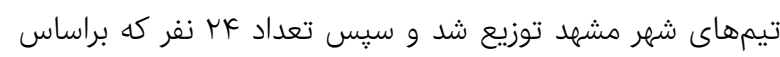
اين يرسشنامه بدون هيج گونه دردى در شانه بودند و هر سه سه

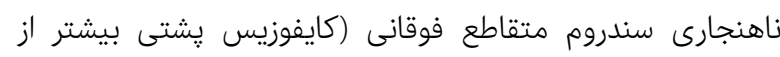

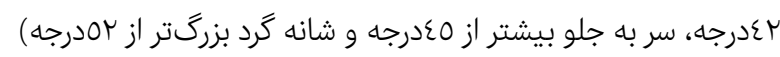

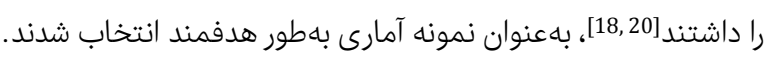
براى تعيين حداقل تعداد نمونه، از نرمافزار

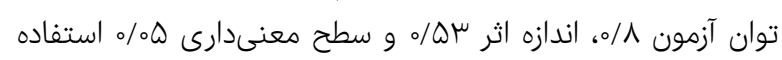

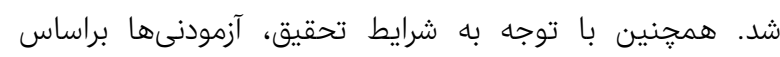

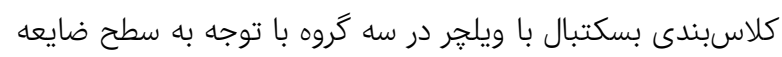

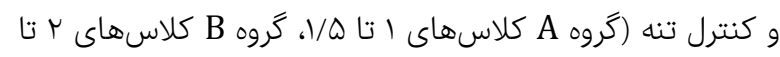

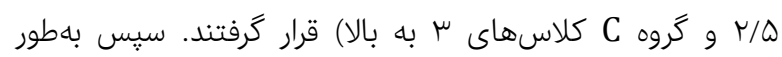

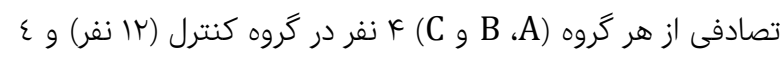

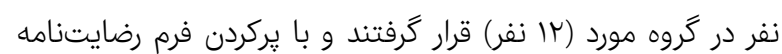

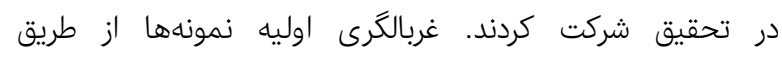

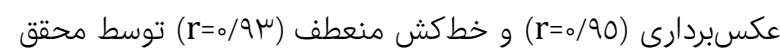

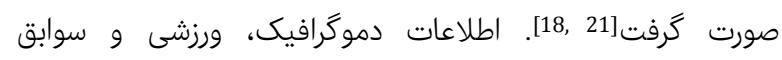

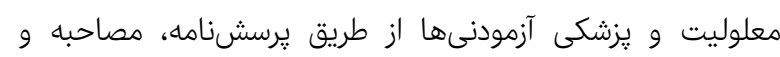

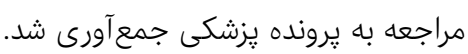

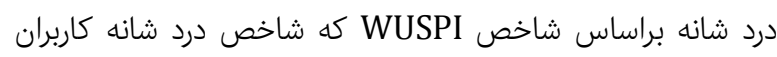

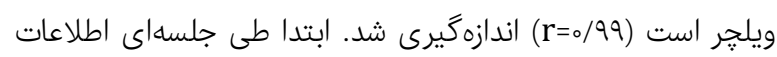

عضلانى است كه در آن بخش فوقانى عضله ذوزنقه و گوشهاى در

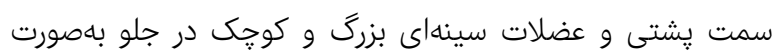

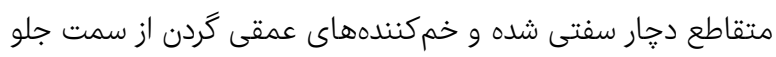

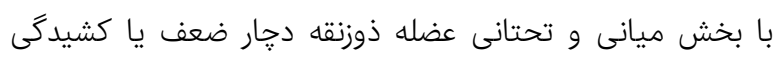

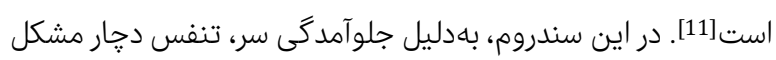
مىشود و احتمال دارد مفصل فكى گيجگًاهى دجار استئوآرتريت

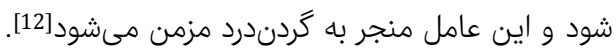
تحقيقات مختلف با اعمال روشهاى تمرينى جداكانه كششى و و

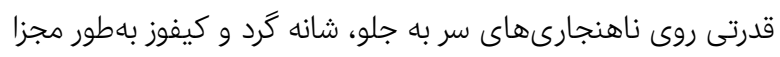
انجام شده است. اما وجود سه ناهنجارى مذكور باريا همديكر نشان از از وجود سندروم متقاطع فوقانى است. سندروم متقاطع فوقانى ندانى

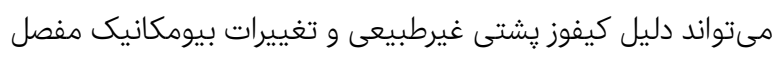

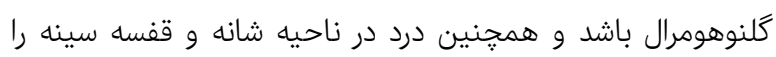

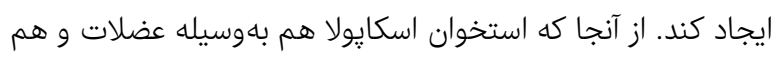

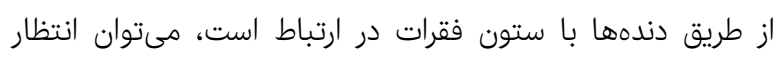

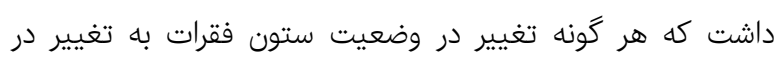

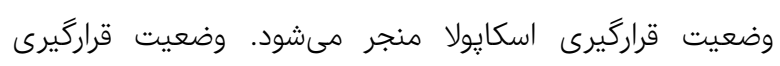

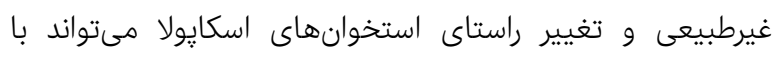
برهمزدن ريتم اسكايولوهومرال، باعث بىثباتى مفصل كلنوهومرال

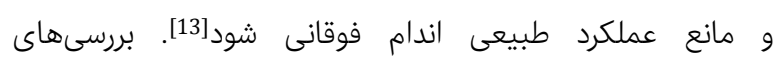

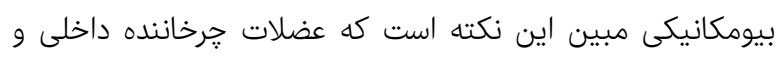

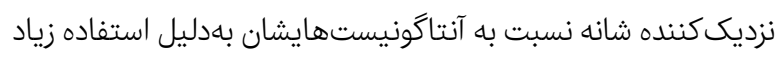

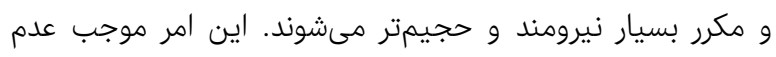

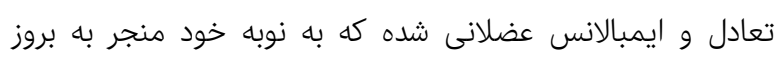

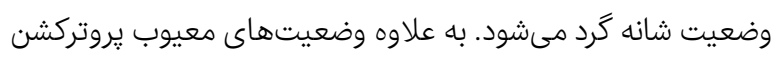

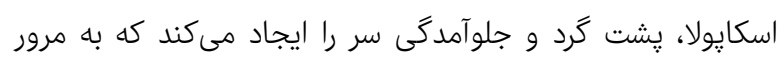
زمان دردناكشدن شانه و كوتاهشدن عضلات قدام شانه نظير يكتوراليسها را به همراه دارد [14].

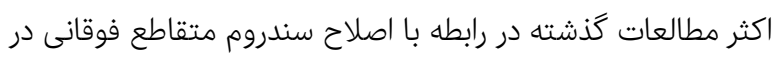

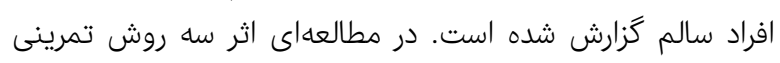

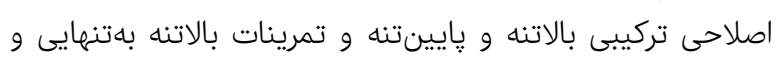

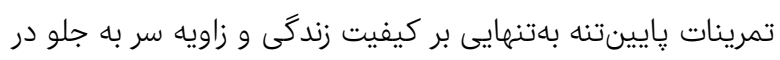

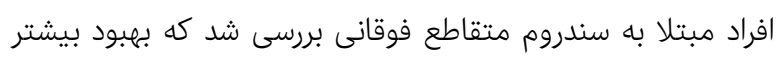

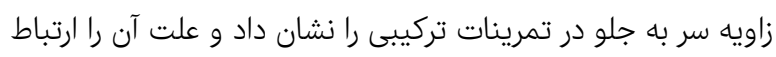

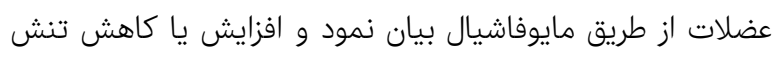

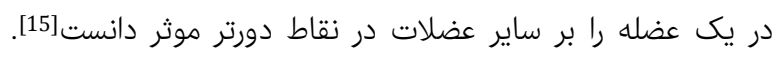

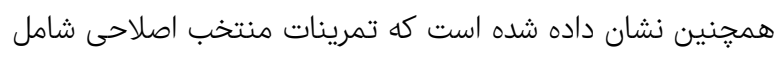

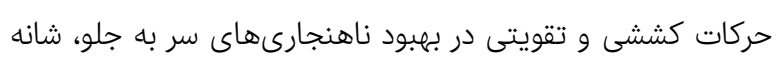

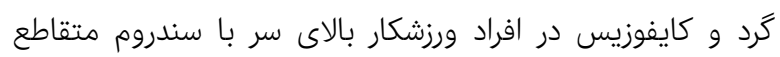
فوقانى موثر است[16]. در مطالعهاى ديكر كاهش معن معنىدارى در در هر

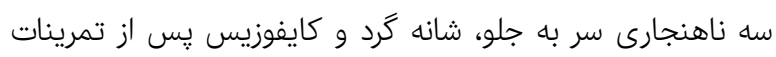
اصلاحى جامع كزارش شد و بر اصلاح هر سله ناهنجارى بله بهانهور

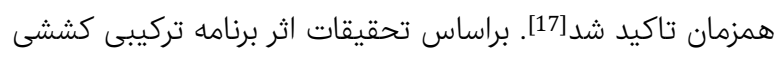
و تقويتى در اصلاح ناهنجارىهاى سر به جلو و كايفوزيس نسبت 
ارزيابى وضعيت جلوآمدگى سر: ميزان زاويه سر به جلو با استفاده از

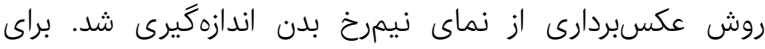

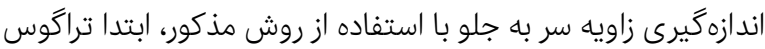

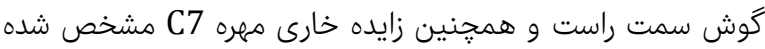

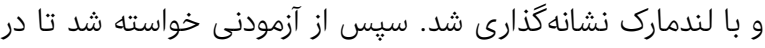

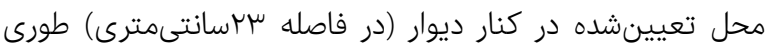

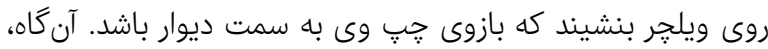

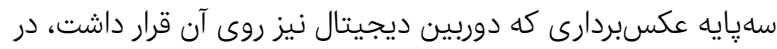

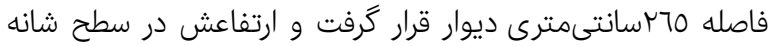

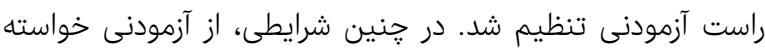

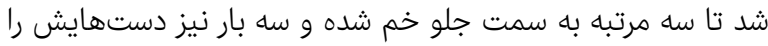

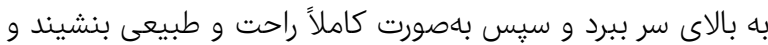

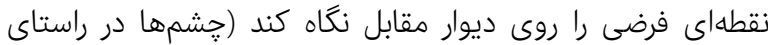

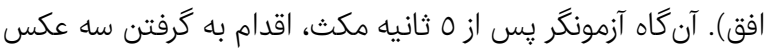

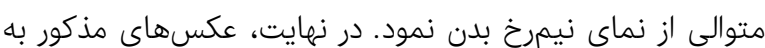

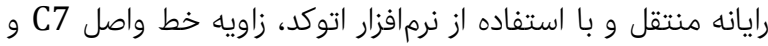

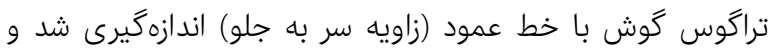

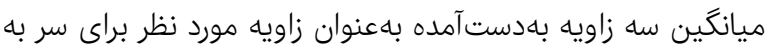

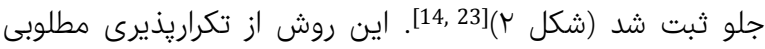

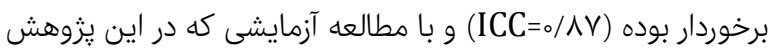

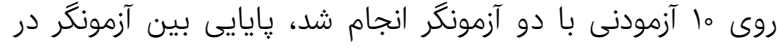

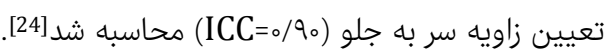

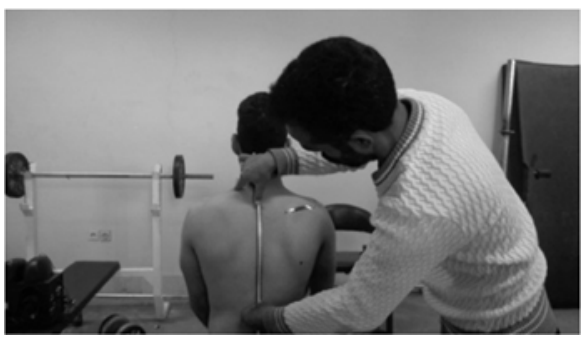

شكل 1) ارزيابى انحناى توراسيك با خطكش منعطف

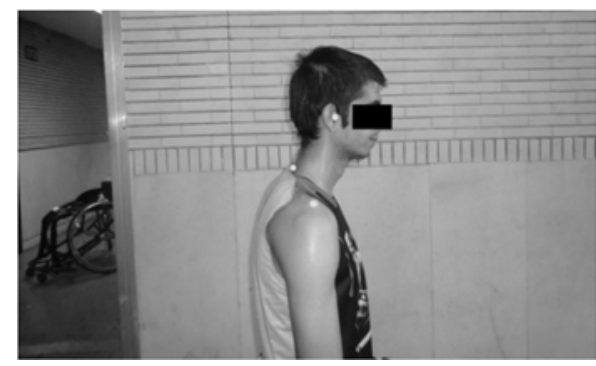

شكل r) ارزيابى جلوآمدگى سر و شانه

يروتكل تمرينى: هر جلسه تمرينى حداكثر ه7 دقيقه شامل ها دقيقه

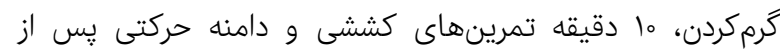
كرمكردن يا سردكردن، حداكثر هب دقيقه تمرئه تمرينات يوسجرال مبتنى بر پايدارسازى اسكايولا و و 1 دقيقه

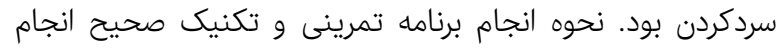

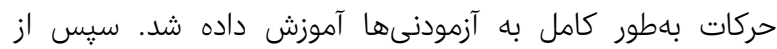

كاملى در مورد هدف تحقيق و نحوه اندازمخيرى ها بها به آزمودنىها داده

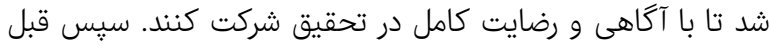

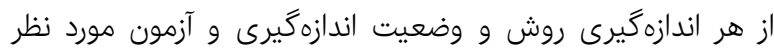

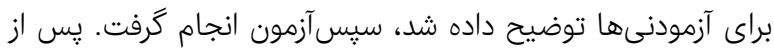

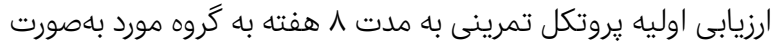

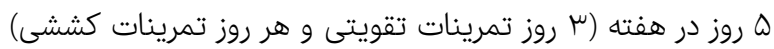
و به مدت هر جلسه حداكثر هو دقيقه (ما دقيقه كرمكردن، ماته

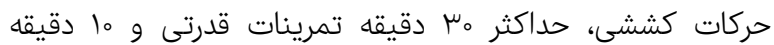

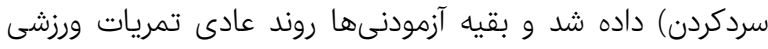

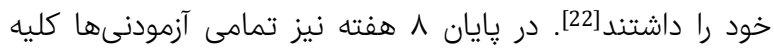

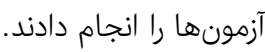

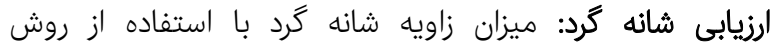

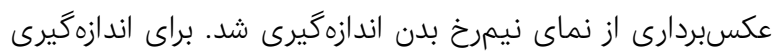

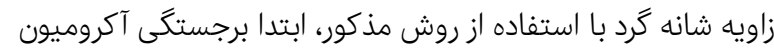

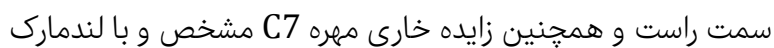

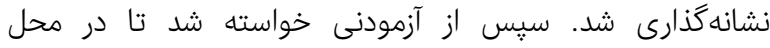

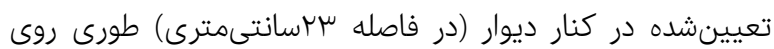

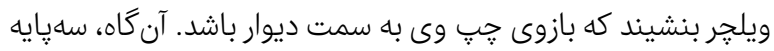
عكسبردارى كه دوربين ديجيتال نيز روى آن قرار داشت، در فاصله

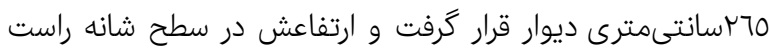

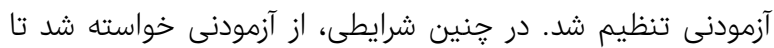

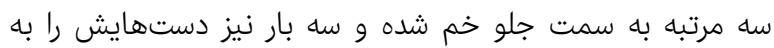

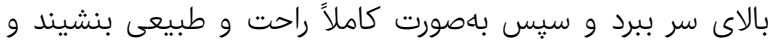

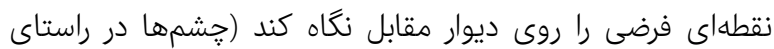

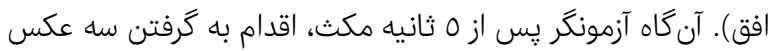

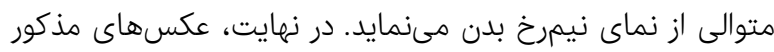

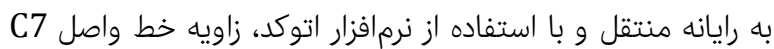

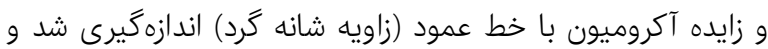

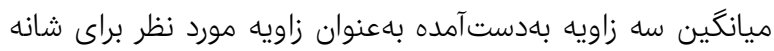

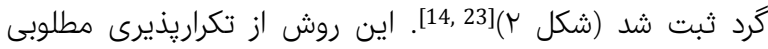

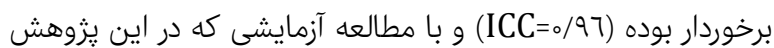

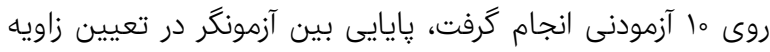

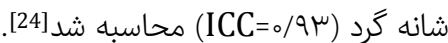
ارزيابى انحناى ستون فقرات توراسيك: براى اندازميرى انحناى

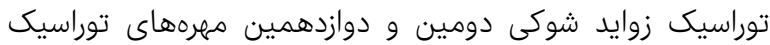

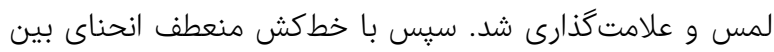

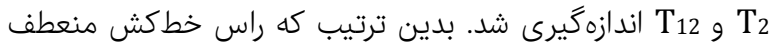

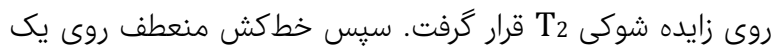

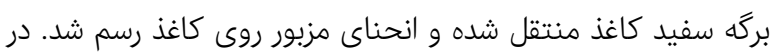

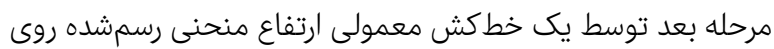
كاغذ اندازمكيرى شد و بعد با كمك معادله

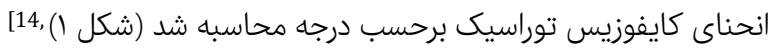

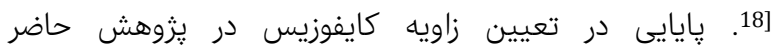
محاسبه شد. (ICC=。/9V) 


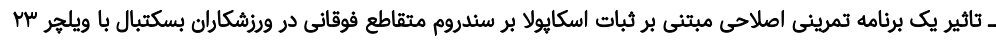

ورزشى) طراحى شد (جدول ()[22,25].

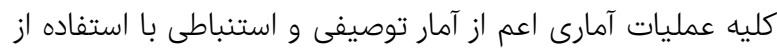

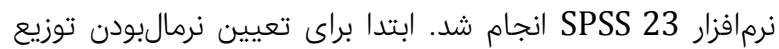

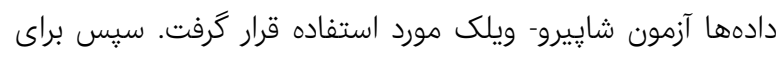

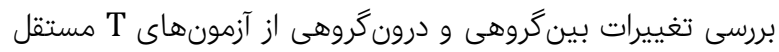

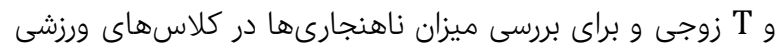

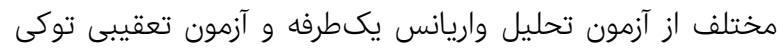

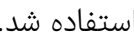

ورزشكاران در هر جلسه خواسته شد كه تمرينات مزبور را براساس آموزشهاى دادهشه توسط مربى بدنساز انجام دهند. علاوه بر اين اين

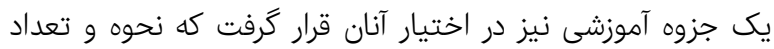

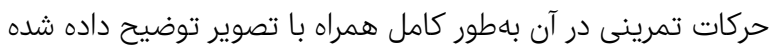

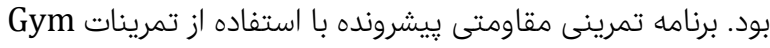
براى افراد داراى ضايعه نخاعى ارايهشه توسط مركز يزشكى بـانى

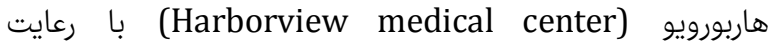
دستورالعمل ارزيابى و تجويز تمرين ACSM (كالج آمريكايى طب

جدول () برنامه تمرينى اصلاحى طى يك جلسه

\begin{tabular}{|c|c|c|c|}
\hline تعداد تكرار & تعداد ست & نام حركت & حركات و عضلات درگير \\
\hline & & & حركت تقويتى \\
\hline 10 & $\mu$ & بالابردن مديسنبال و ميله & عضله دلتوئيد \\
\hline 10 & $\mu$ & كشش لتيول و اكستنشن شانه & عضله يشتى بزرگ \\
\hline 1. & $\mu$ & ديе با بازوى باز & عضله ذوزنقه تحتانى \\
\hline 10 & $\mu$ & كشش ڤارو و حركت بروانه با وزنه آزاد & تحتانى مضوازى الاضلاع و ذوزنقه ميانى و \\
\hline 1. & $\mu$ & اينترنال روتيشن و اكسترنال روتيشن بازو با وزنه & عضلات رتيتوركاف \\
\hline 10 & $\mu$ & 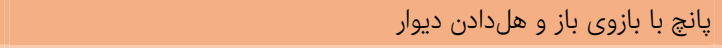 & عضله دندانهاى قدامى \\
\hline 10 & $\mu$ & اكستنشن بازو با وزنه & سهسر بازو \\
\hline 10 & $\mu$ & نزديككردن קانه به قفسه سينه در حالت خوابيده به يشت & عضله خمكننده عمقى كردن \\
\hline \multirow{4}{*}{ م تكرار مسثانيهاى } & & & حركت كششى \\
\hline & \multirow{3}{*}{$\mu$} & كشش در حالتى كه شانهها در وضعيت ابداكشن •ودرجه و آرنجها نيز در & \multirow{3}{*}{ عضله سينهاى بزرگ } \\
\hline & & فلكشن •qدرجه قرار دارند، دستها روى ديوار قرار مى & \\
\hline & & سينه كشش در ناحيه عضلات سينهاى ايجاد مىشود. & \\
\hline \multirow[t]{2}{*}{ 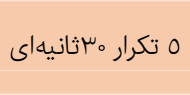 } & \multirow[t]{2}{*}{$\mu$} & مربى با فشار بر سرشانه در حالت خوابيده به يشت سعى در رساندن سطح & \multirow{2}{*}{ عضله سينهاى كوجٍى } \\
\hline & & خلفى كتف ورزشكار به تشك را دارد. & \\
\hline \multirow[t]{2}{*}{ 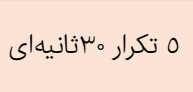 } & \multirow[t]{2}{*}{$\mu$} & يك دست به بدنه ويلجر براى ثبات تنه و دست ديخر در يك طرف سر قرار & \multirow[t]{2}{*}{ عضله ذوزنقه بالايى } \\
\hline & & داده مىشود و آن را بدون خرخش به سمت ديكر خم مىكند. & \\
\hline
\end{tabular}

معنىدارى نداشت (D>0/p)، اما در گروه مورد اين ناهنجارىها در

يافتهها

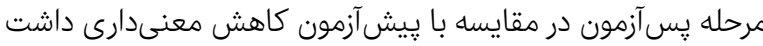

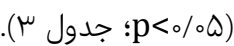

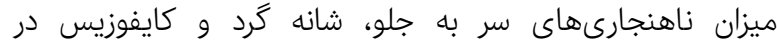

كلاسهاى ورزشى مختلف تفاوت معنىدارى داشت (جدول عارى). يس از مقايسه دوبهدوى كلاسهاى ورزشى، ميزان ناهنجارىهاى

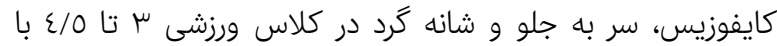

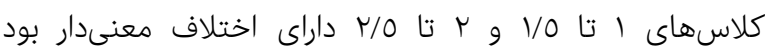

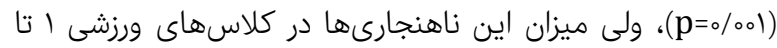

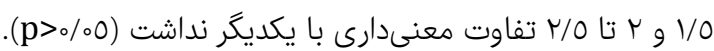
بين دو گروه كنترل و مورد از نظر متغيرهاى دموگرافيك سن، وزن

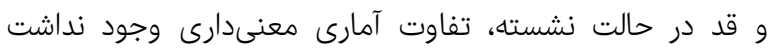

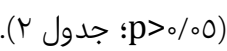
در ييشآزمون، بين دو گروه كنترل و مورد از نظر ميزان كايفوزيس،

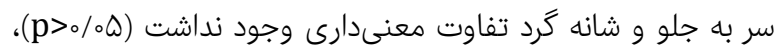

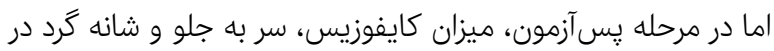

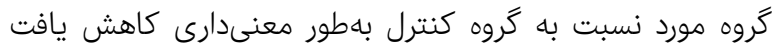
(p<o/oD)

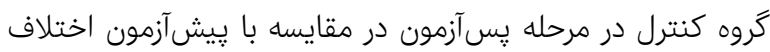

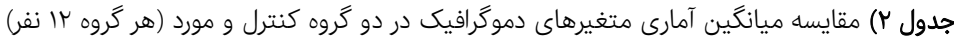

\begin{tabular}{|c|c|c|c|c|}
\hline سطح معنىدارى & مقدار t & كروه مورد & كروه كنترل & متغيرهاى دموگرافيك \\
\hline$\circ / \uparrow \wedge$ & $1 / 10$ & $\mu q / \circ \wedge \pm \Delta / \circ \wedge$ & $\varepsilon \mu / \circ \pm \| 11 / \mu \mu$ & سن (سال) \\
\hline$\% \% 9$ & I/V\& & $0 \varepsilon / 0 \bullet \pm \Lambda / V^{\mu}$ & $71 / \% 0 \pm 9 / 91$ & وزن (كيلوگرم) \\
\hline ॰/Q。 & $0 / \& V$ & VV/TOE & VA/TO $\pm \Psi / ৭ 0$ & قد نشسته (سانتىمتر) \\
\hline
\end{tabular}


ج FF عبدالله معروف و همكاران

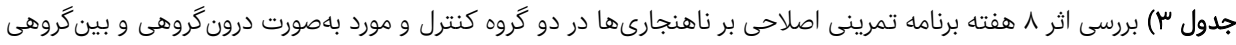

\begin{tabular}{|c|c|c|c|}
\hline نتايج آزمون T مستقل & كروه مورد & گروه كنترل & متغيرها \\
\hline & & & كايفوزيس (درجه) \\
\hline $\mathrm{p}=\circ / \mathrm{qK}: \mathrm{t}=\mathrm{o} / \circ \mathrm{V}$ & $\Delta s / \backslash \varepsilon \pm r / F \wedge$ & $\Delta \& / r \Delta \pm r / \wedge q$ & بيش آزمون \\
\hline$p=\circ / \circ \mu^{\mu}: t=\mu / \mu q$ & $\Delta r / 91 \pm r / 19$ & $\Delta \varphi / \mu \mu_{ \pm}+V_{0}$ & لِ \\
\hline- & $\mathrm{p}=0 / 001: \mathrm{t}=9 / \sim \varepsilon$ & $\mathrm{p}=\mathrm{o} / \mathrm{V} \mathrm{t} \mathrm{t}=\mathrm{o} / \mathrm{T}^{-}$ & نتايج آزمون T زوجى \\
\hline & & & سر به جلو (درجه) \\
\hline $\mathrm{p}=\circ / \neg \mu \mathrm{t}=0 / \circ \wedge$ & $\Delta 1 / r \Delta \pm r / F q$ & $\Delta l / r \mu w \pm r / K q$ & بيش آزمون \\
\hline$p=0 / 001: t=K / D \mid$ & $\mid \nvdash V / \wedge \notin \pm Y / \wedge q$ & $\Delta I / r \mu \pm r / \Delta V$ & لِس آزمون \\
\hline - & $\mathrm{p}=\circ / \circ 01: t=q / \circ k$ & $p=1 / \circ: t=0 / .001$ & نتايج آزمون T زوجى \\
\hline & & & شانه گرد (درجه) \\
\hline $\mathrm{p}=0 / \mathcal{G} \mu \mathrm{t}=\mathrm{o} / \mathcal{K} V$ & $\Delta S / \Delta \Lambda \pm r / \Delta V$ & $\Delta S / \circ \Lambda \pm Y / \Delta V$ & رِيش آزمون \\
\hline $\mathrm{p}=0 / \circ 01: \mathrm{t}=r / V \varphi$ & $\Delta 1 / \wedge \mu_{ \pm} r / \varphi q$ & $\Delta \varepsilon / 0 \circ \pm r / V \mu$ & لِ يس آزمون \\
\hline- & $\mathrm{p}=\mathrm{o} / 001: \mathrm{t}=11 / \Delta \mathrm{V}$ & $\mathrm{p}=\mathrm{o} / \mathrm{V}: \mathrm{t}=\mathrm{o} / \mathrm{Tq}$ & نتايج آزمون T زوجى \\
\hline
\end{tabular}

\begin{tabular}{|c|c|c|c|c|c|}
\hline سطح معنىدارى & Fقدار F مق F & كلاس س تا ع/ه & كلاس r تا ه/r & كلاس اتا ه/ & متغيرها \\
\hline \%०ol & $\mu / / \Lambda \Lambda$ & $\Delta \Psi / I Y \pm I / Q \Delta$ & $\Delta V / \backslash r \pm 0 / 99$ & $\Delta \Lambda / \mu \bigvee \pm 1 / \omega_{0}$ & كايفوزيس (درجه) \\
\hline$\% 001$ & $\mu / / 90$ & $K \wedge /{ }^{\gamma} Y_{ \pm 0} / V K$ & $\Delta r / \Delta \circ \pm 1 / \Delta I$ & $\Delta \mu / \circ \circ \pm 1 / 41$ & سر به جلو (درجه) \\
\hline$\% 001$ & $17 / \mathrm{VT}$ & $\Delta \mu / \Lambda \vee \pm r / \circ \mu$ & $\Delta \& / Q_{\circ} \pm 1 / Q 1$ & $\Delta \Lambda / \varepsilon \gamma \pm 1 / \mu_{0}$ & شانه گرد (درجه) \\
\hline
\end{tabular}

يكبعدى، در معرض ابتلا به ناهنجارىهاى سر به جلو و افزايش

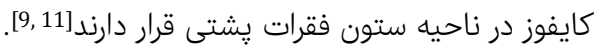

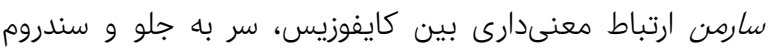

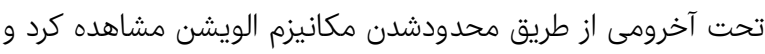

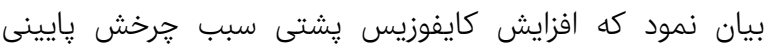

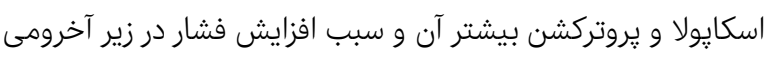
و بافتهاى زير آن مانند كيسه زلالى و تاندون رتيتوركاف مى بـ آشود.

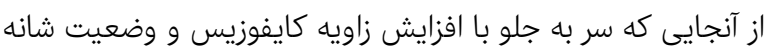

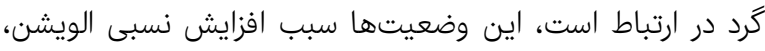
يروتركشن، جرخش تحتانى و تيلت قدامى اسكايولا مىشود

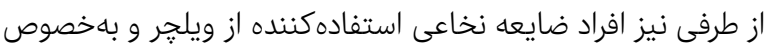

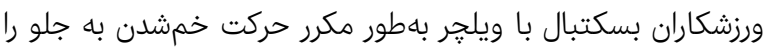

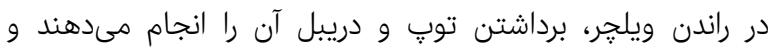

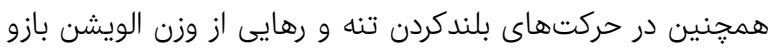

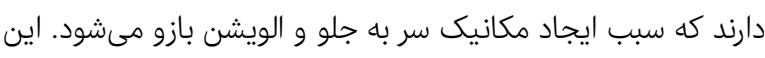

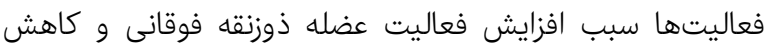

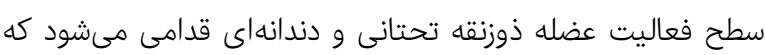
با نظر جاندا مبنى بر استعداد ضعف در عضله دندانهاى قدامى مطابقت دارد.

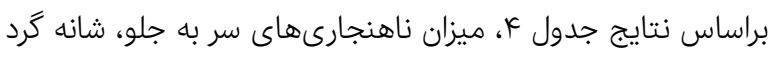

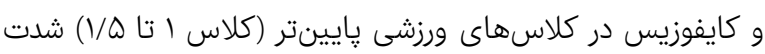

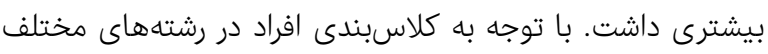

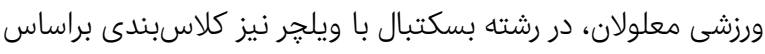

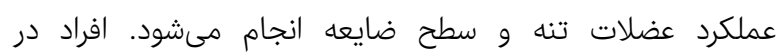

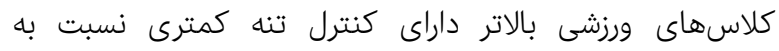
كلاسهاى يايينتر هستند و اين بهدليل عدم عصبرسانى به داريه

نتايج مطالعات مختلف نشاندهنده تاثير مطلوب تمرينات اصلاحى

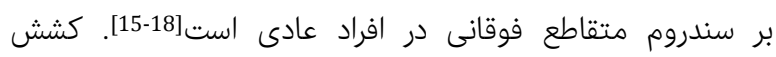

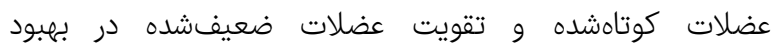

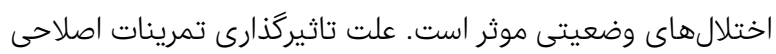

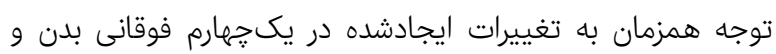

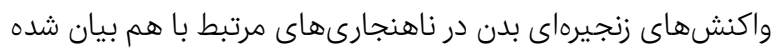
است[17]. همجنين تاثيرگذارى تمرينات تركيبى نسبت به تمرئ درينات مجزاى كششى و تقويتى بيشتر است و توجه همزمان به تغييرات

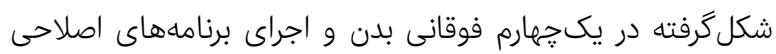

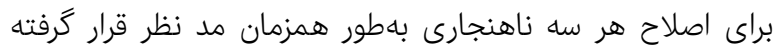

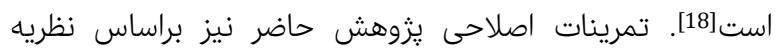

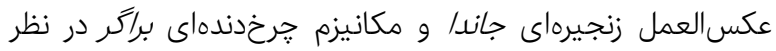

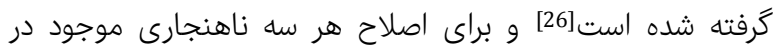
سندروم متقاطع فوقانى است. سيستم اسكلتى همانند يك زنجيره

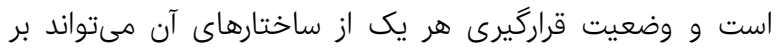

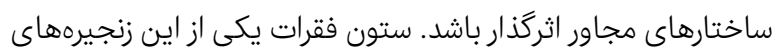

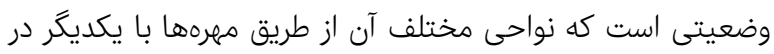

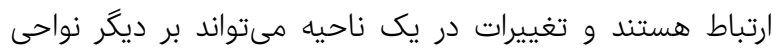

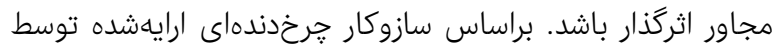
براكر وضعيت نشسته ضعيف سبب جرخش خلفى لكن مى شاشود كه

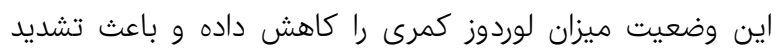

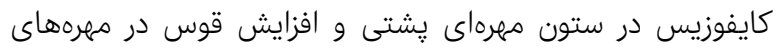

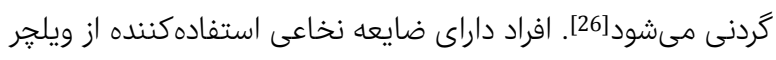
بهدليل عدم تعادل در عضلات تنه و وضعيتهاى غرداى غلط نشستن

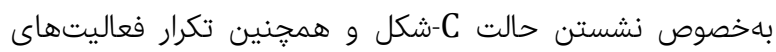




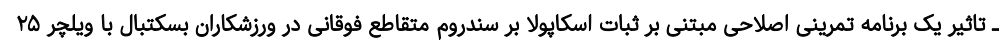

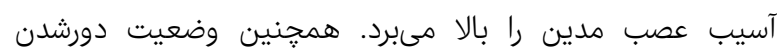

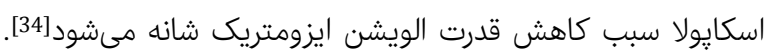

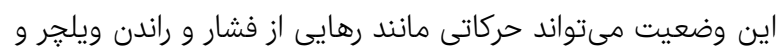

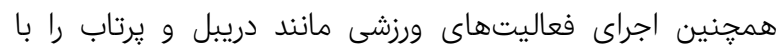

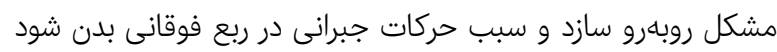

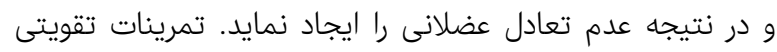

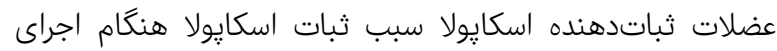

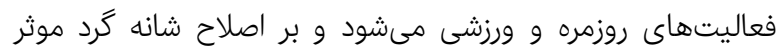

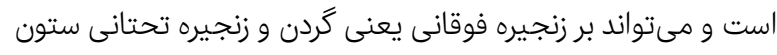

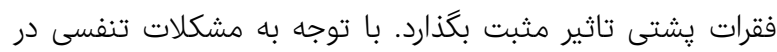

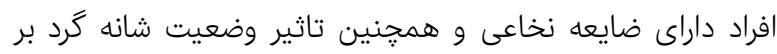

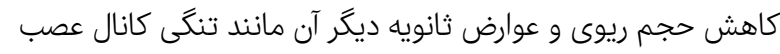
و اختلالات ريتم اسكايولا، اصلاح اين ناهنجارى در اين افراد ضرورى

به نظر مىرسد [33]. نتايج يزوهش حاضر نشان داد كه ميزان كايفوزيس در افراد كروه

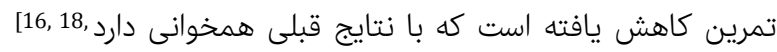
[19. برخى مطالعات تمرينات جامع را در كاهش كايفوزيس بر بر فيته

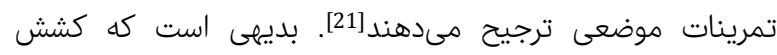

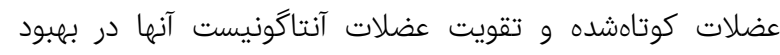

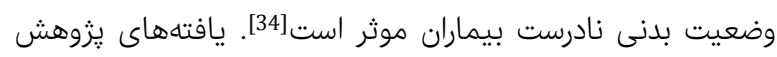
حاضر بر كاهش ميزان كايفوزيس در افراد ضايعه نخاعى بسكتبال

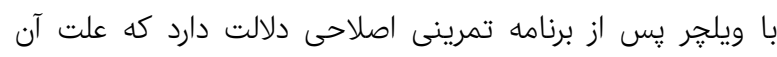

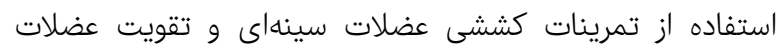

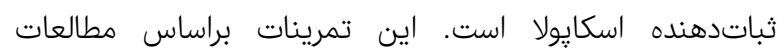

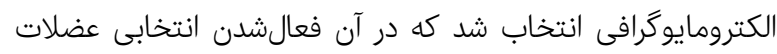

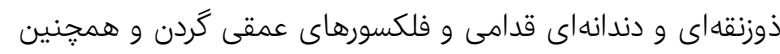

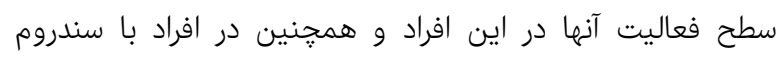

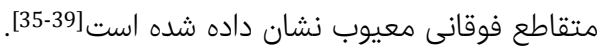

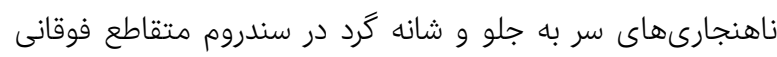
سبب تغييرات عصبى- عضلانى- اسكلتى و اختلال در وضعيت اسكايولا مىشود كه ايمبالانسهاى عضلانى در كمربند شانهاى و

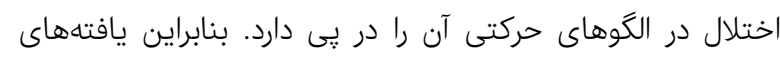

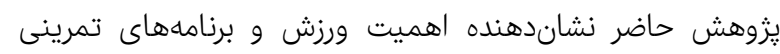
اصلاحى بهخصوص تمرينات ثباتدهنده اسكايولا در افراد ضايعه

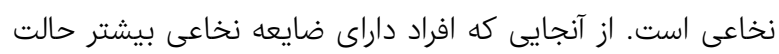

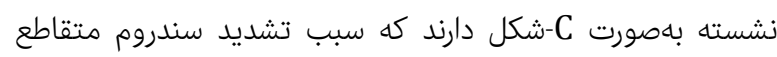
فوقانى در آنها مىشود و همجنين ورزشكاران بسكتبال با ويلجر

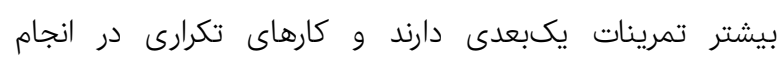
فعاليتهاى ورزشى كه تشديدكننده اين سندروم است را زياد انجام

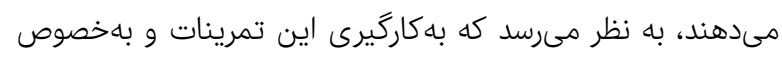

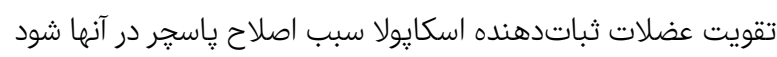

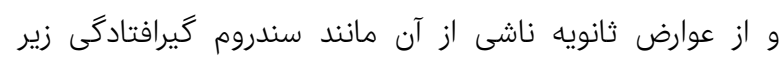

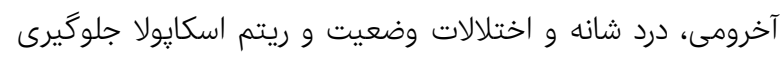

نمايد.
عضلات تنه است كه كنترل تنه و ستون فقرات را با مشكل مواجه مىنمايد[7]. در ناهنجارى كايفوزيس، اين نتايج مشابه نتايج

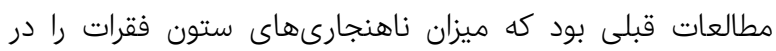
سطوح بالاتر ضايعه بيشتر گزارش كردند.

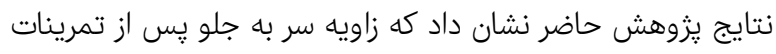

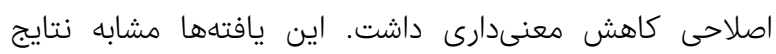

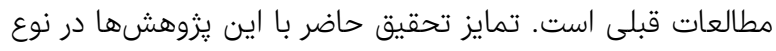
نمونه بود كه در اين تحقيق نمونهها، بازيكنان بسكتبال با ويلجر

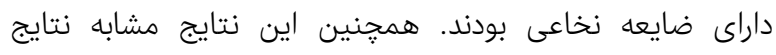

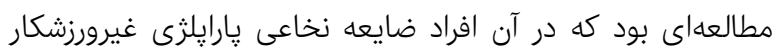

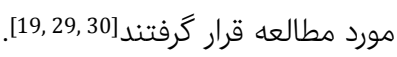
از آنجايى كه بين سردرد و گردندرد با زاويه سر به جلو ارتباط وجود كرد

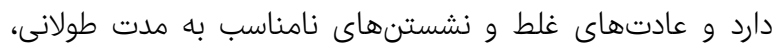

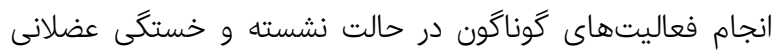

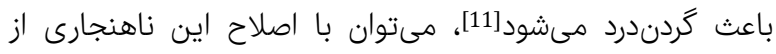

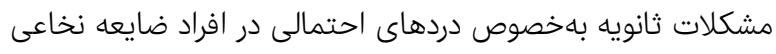

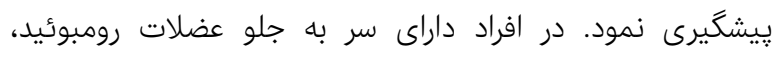

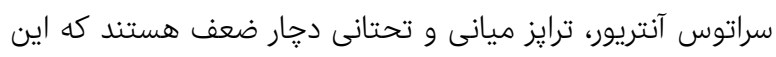
عدم تعادل عضلانى با درد و خستخى در ناحيه گردن همراه است] [31].

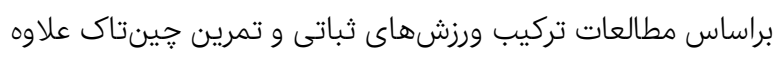

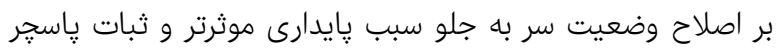
مىشود[32] كه تمرينات كششى و تقويتى در تحقيق حاضر بر بايه تقويت عضلات ثباتدهنده اسكايولا انجام كرفت

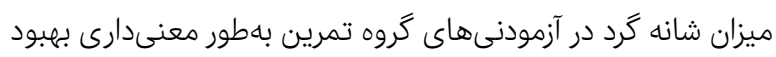

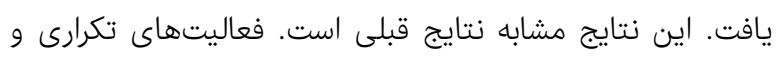

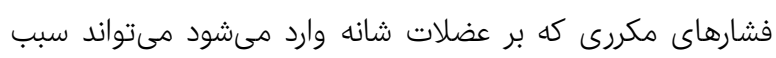

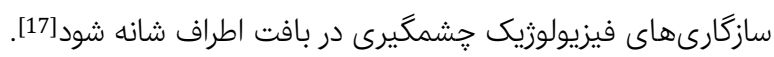

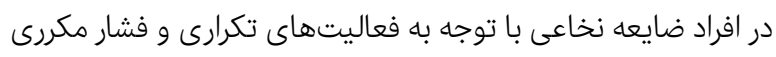

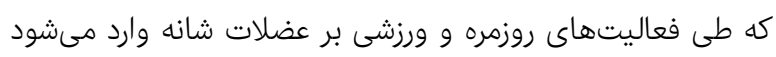

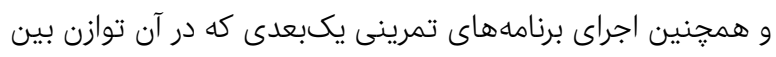

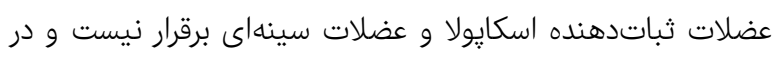

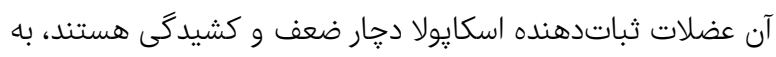
نظر مىرسد كه اجراى برنامههاى اصلاحى مبتنى بر ثبات اسكايولا

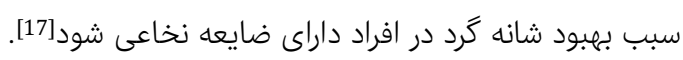

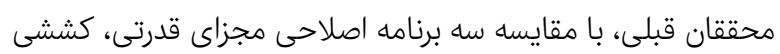

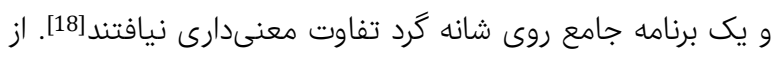

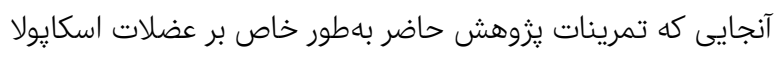

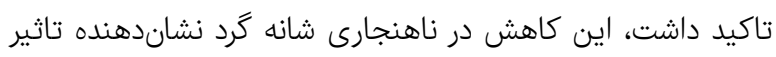

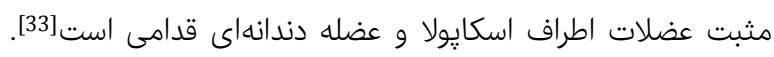
ثباتدهندههاى اصلى اسكايولا عضلات رومبوئيد، ذوزنقه، بالابرنده

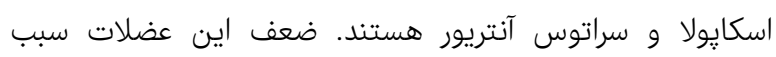

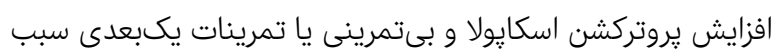

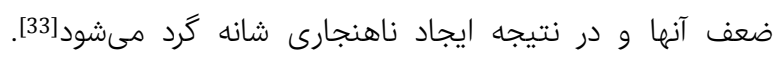

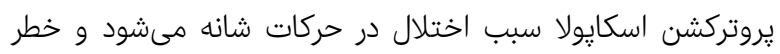


3- Vanlandewijck YC, Verellen J, Tweedy S. Towards evidence-based classification in wheelchair sports: impact of seating position on wheelchair acceleration. J Sports Sci. 2011;29(10):1089-96.

4- Dec KL, Sparrow KJ, McKeag DB. The physicallychallenged athlete: medical issues and assessment. Sports Med. 2000;29(4):245-58.

5- Miyahara M, Sleivert GG, Gerrard DF. The relationship of strength and muscle balance to shoulder pain and impingement syndrome in elite quadriplegic wheelchair rugby players. Int J Sports Med. 1998;19(3):210-4.

6- Saberi M, Ebrahimi Atri A, Hashemi Javaheri SAA, Khodaei M. Comparison of line of the spine veterans spinal cord injured athletes in The various sports groups. Iran J War Public Health. 2012;4(16):13-20. [Persian]

7- Marouf A. The survey of spinal alignment and physical fitness of disabled with spinal cord injuries [Dissertation]. Rasht: Guilan University; 2010. [Persian]

8- Bergström EMK, Short DJ, Frankel HL, HendersonNJ, Jones PRM. The effect of childhood spinal cord injury on skeletal development: a retrospective study. Spinal Cord. 1999;37:838-46.

9- Minkel JL. Seating and mobility considerations for people with spinal cord injury. Phys Ther. 2000;80(7):701-9.

10- Hastings JD, Fanucchi ER, Burns SP. Wheelchair configuration and postural alignment in persons with spinal cord injtry. Arch Pbys Med Rebabil. 2003;84(4):528-34.

11- Janda V, Grant R. Muscles and cervical pain syndromes. In: Grant R, editor. Physical therapy of cervical and thoracic spine. New York: Churchill Livingstone; 1988. p. 153-66.

12- Clark M, Lucett S. NASM essentials of corrective exercise training. Philadelphia, Pa: Lippincott Williams Wilkins Publication; 2010. p. 9-75.

13- Teixeira FA, Carvalho GA. Reliability and validity of thoracic kyphosis measurements using flexicurve method. Braz J Phys Ther. 2007;11(3):199-204.

14- Sepehrifar S, Moezi A, Soleimani Dodaran M. The effect of 6-week exercise therapy protocol on scapular position, head, shoulder and thoracic posture in patients with shoulder overuse syndrome. J Nurse Physician War. 2014;2(3):53-63. [Persian]

15- Rostami Zalani F, Ahanjan S, Roshani S, Bagherian Dehkordi S, Falah AR. Comparison of the effects of three corrective exercise methods on the quality of life and forward head of men with upper cross syndrome. J Paramed Sci Rehabil. 2019;8(1):26-36. [Persian]

16- Cheshmi S, Alizadeh MH, Barati AH, Akouchekian M. the effect of six weeks corrective exercise on uppercrossed syndrome of overhead athletes. J Appl Exerc Physiol. 2018;14(27):153-66. [Persian]

17- Daneshmandi H, Mogharrabi Manzari M. The effect of eight weeks comprehensive corrective exercises on upper crossed syndrome. Sci J Manag Syst. 2014;12(7):75-86. [Persian]

18- Hajihosseini E, Norasteh AA, Shamsi A, Daneshmandi $\mathrm{H}$. The comparison of effect of three programs of strengthening, stretching and comprehensive on upper crossed syndrome. J Res Rehabil Sci. 2015;11(1):51-61. [Persian]

19- Roshani S, Mahdavinejad R, Ghanizadeh N. The effect of a NASM-based training protocol on upper cross syndrome in paraplegia spinal cord injury patients. J Ilam Univ Med Sci. 2018;25(6):73-85. [Persian]

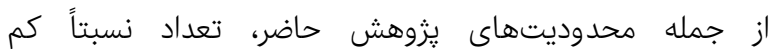
آزمودنىهاى بهدليل عدم دسترسى و شرايط مطالعه، همجنين عدم كنترل كامل آزمودنى در انجام برنامه تمرينى (بهدليل مشكلات ثانويه ناشى از ضايعه نخاعى) بود.

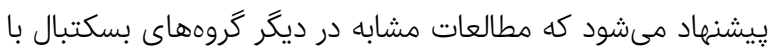

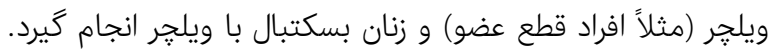
همجنين تاثير برنامههاى تمرينى ديكر بر سندروم متقاطع فوقانى

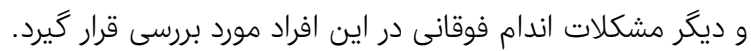

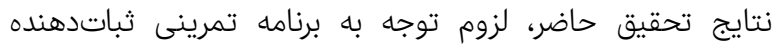
اسكايولا را در طراحى برنامههاى تمرينى اصلاحى براى ورزشكاران

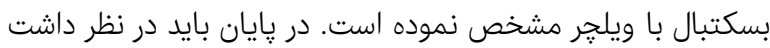

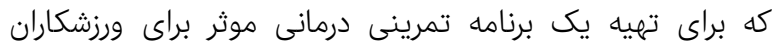

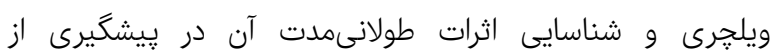

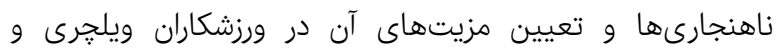
بهخصوص بازيكنان بسكتبال با ويلجر، نياز به تحقيقات بيشتر است دريت.

\section{نتيجه گيرى}

تمرينات اصلاحى مبتنى بر ثبات اسكايولا در بهبود ناهنجارىهاى

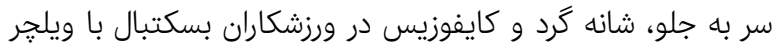

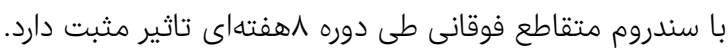

تشكر و قدردانى: از ورزشكاران بسكتبال با ويلجر جانباز و معلول مراكز

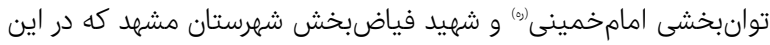
يثروهش مشاركت داشتند، تشكر و قدردانى مى قشود.

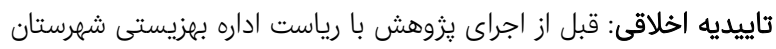

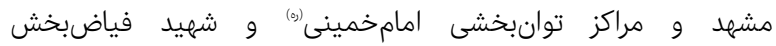

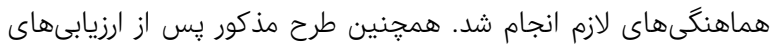

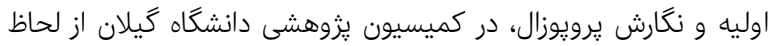

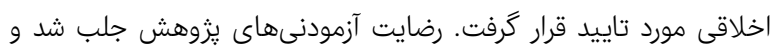

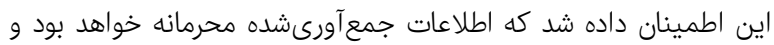

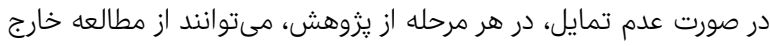
تعارض منافع: تعارض منافع با شخص يا سازمانى وجود ندارد.

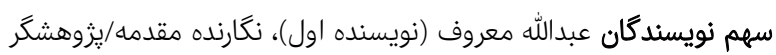

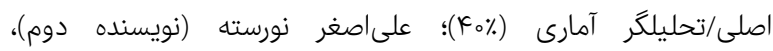

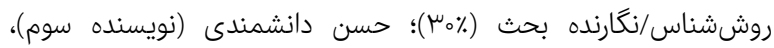

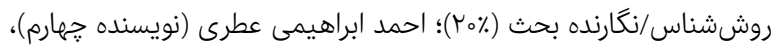

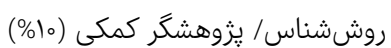
منابع مالى: اين يزوهش مستخرج إز رهشر كمكى (هاله دكتراى نويسنده اول مقاله

\section{منابع}

1- Klenck C, Gebke K. Practical management: common medical problems in disabled athletes. Clin J Sport Med. 2007;17(1):55-60.

2- Goosey-Tolfrey V. Supporting the paralympic athlete: focus on wheeled sports. Disabil Rehabil. 2010;32(26):2237-43. 
تاثير يك برنامه تمرينى اصلاحى مبتنى بر ثبات اسكايولا بر سندروم متقاطع فوقانى در ورزشكاران بسكتبال با ويلحر

Medical Publishing; 2010. p. 90

30- Diab AA, Moustafa IM. The efficacy of forward head correction on nerve root function and pain in cervical spondylotic radiculopathy a randomized trial. Clin Rehabil. 2012;26(4):351-61.

31- Moore MK. Upper crossed syndrome and its relationship to cervicogenic headache. J Manipulative Physiol Ther. 2004;27(6):414-20.

32- Hertling D, Kessler RM. Management of common musculoskeletal disorders. Physical therapy principles and methods. $4^{\text {th }}$ Edition. Philadelphia, Pa: Lippincott Williams Wilkins Publication; 2006. p. 231.

33- Najafi M, Behpoor N. The effects of a selective corrective program on the scapula and shoulder joint posture in girls with rounded shoulder. J Sport Med. 2013;4(2):31-47. [Persian]

34- Kotteeswaran K, Rekha K, Anandh V. Effect of stretching and strengthening shoulder muscles in protracted shoulder in healthy individuals. Int J comput Appl. 2012;2(2):111-18.

35- Ekstrom RA, Donatelli RA, Soderberg GL. Surface electromyographic analysis of exercises for the trapezius and serratus anterior muscles. J Orthop Sports Phys Ther. 2003;33(5):247-58.

36- Falla D, Jull G, Russell T, Vicenzino B, Hodges P. Effect of neck exercise on sitting posture in patients with chronic neck pain. Phys Ther. 2007;87(4):408-17.

37- Falla D, O'Leary S, Fagan A, Jull G. Recruitment of the deep cervical flexor muscles during a postural-correction exercise performed in sitting. Man Ther. 2007;12(2):13943.

38- McClure PW, Bialker J, Neff N, Williams G, Karduna A. Shoulder Function and 3- Dimensional Kinematics in People With Shoulder Impingement Syndrome Before andAfter a 6 Week Exercise Program. Phys Ther. 2004;84(9):832-48.

39- O'Leary S, Falla D, Jull G, Vicenzino B. Muscle specificity in tests of cervical flexor muscle performance. J Electromyogr Kinesiol. 2007;17(1):35-40.
20- Thigpen CA, Padua DA, Michener LA, Guskiewicz K, Giuliani C, Keener JD, et al. Head and shoulder posture affect scapular mechanics and muscle activity inoverhead tasks. J Electromyogr Kinesiol. 2010;20(4):701-9.

21- Morningstar M. Cervical curve restoration and forward head posture reduction for the treatment of mechanical thoracic pain using the pettibon corrective and rehabilitative procedures. J Chiropr Med. 2002;1(3):113-5.

22- Pescatello LS. ACSM's guidelines for exercise testing and prescription. 9th Edition. Philadelphia: Wolters Kluwer/Lippincott Williams \& Wilkins Health; 2014.

23- Seidi F, Rajabi R, Ebrahimi E, Alizadeh MH, Daneshmandi $H$. The effect of a 10-week selected corrective exercise program on postural thoracic kyphosis deformity. J Sport Med. 2013;5(1):5-22. [Persian]

24- Ruivo RM, Pezarat-Correia P, Carita AI. Intrarater and interrater reliability of photographic measurement of upper-body standing posture of adolescents. J Manipulative Physiol Ther. 2015;38(1):74-80.

25- Harborview Medical Center. Gym based exercises for SCI [Internet]. Washington: University of Washington Medicine; 2013 [cited 2018 Feb 16]. Available from: http://sci.washington.edu/info/forums/reports/exercis e_2013.asp.

26- Page P, Frank CC, Lardner R. Assessment and treatment of muscle imbalance: the Janda approach. Champaign: Human Kinetics; 2010.

27- Kebaetse M, McClure P, Pratt NA. Thoracic position effect on shoulder range of motion, strength, and threedimensional scapular kinematics. Arch Phys Med Rehabil. 1999;80(8):945-50.

28- Ryan SD, Fried LP. The impact of kyphosis on daily functioning. J Am Geriatr Soc. 1997;45(12):1479-86.

29- Lin VW, Bono, Cardenas DD, Frost FS, Hammond MC, Lindblom LB, et al, editors. Spinal cord medicine, principles and practice, $2^{\text {nd }}$ Edition. New York: Demos 